\title{
Por que e para que vivemos? Qual sentido damos à existência humana?
}

\section{Por qué y para qué vivimos? Qué sentido le damos a la existencia humana?}

Why and what do we live for? What meaning do we give human existence?

\author{
Sandra Pottmeier ${ }^{\mathrm{a}}$ @, Lais Oliva Donida ${ }^{\mathrm{b}}$ @ , Caique Fernando da Silva Fistarol $^{c}$ \\ ${ }^{a}$ Universidade Federal de Santa Catarina. Mestre em Educação pela Universidade Regional de Blumenau. Doutora pelo Programa de \\ Pós-Graduação em Linguística da UFSC. Docente na rede pública estadual de ensino de Santa Catarina. pottmeyer@gmail.com \\ ${ }^{\text {b }}$ Fonoaudióloga, mestra e doutoranda em Linguística pela Universidade Federal de Santa Catarina. lais.donida@gmail.com. \\ c Mestre em Educação pelo Programa de Pós-Graduação da Universidade Regional de Blumenau. Atua na Secretaria Municipal de \\ Educação de Blumenau (SEMED). cfersf@gmail.com.
}

Resenha de: CORTELLA, Mario Sergio; KARNAL, Leandro. Viver, a que se destina? Campinas, SP: Papirus 7 Mares, 2020, p. 120.

Viver, a que se destina? é uma obra disposta em 120 páginas lançada em 2020 pela editora Papirus 7 Mares. Escrita por Mario Sergio Cortella, filósofo formado na Faculdade de Filosofia Nossa Senhora da Medianeira, mestre e doutor em Educação com ênfase em Currículo pela Pontifícia Universidade Católica de São Paulo, instituição esta onde atuou como professor no Programa de Pós-Graduação em Educação e; por Leandro Karnal, historiador graduado pela Universidade do Vale do Rio dos Sinos e doutor em História Social pela Universidade de São Paulo, professor no departamento de História pelo Instituto de Filosofia e Ciências Humanas da Universidade Estadual de Campinas.

Em tempos de pandemia provocada pelo novo coronavírus (Covid-19), a temática abordada pelos autores exige do leitor reflexões acerca da existência da humanidade em sociedade. Viver, a que se destina? promove, a partir das provocações de Cortella e Karnal (2020), indagações como: quais

Como citar o artigo: POTTMEIER, S.; DONIDA, L.O.; FISTAROL, C.F.S. Por que e para que vivemos? Qual sentido damos a existência humana? Revista de Ciências Humanas, Florianópolis, v . 54, 2020 DOI: 10.5007/21784582.2020.e74009 você pode compartilhar, adaptar, para qualquer fim, desde que atribua a autoria da obra, forneça um link para a licença, e indicar se foram feitas alterações. 
seriam nossos propósitos enquanto seres humanos? Quais seriam nossas escolhas e as rotas que traçamos durante o trajeto de nossa vida? Trata-se de uma produção voltada a qualquer público interessado pelo conteúdo tecido com muito esmero pelos autores. É leitura indispensável a todo e qualquer ser humano que lança olhar para si e para outro, e que tem compreensão de suas ações e do outro e de que maneira isso pode ou não impactar ou implicar em outras ações, boas ou não tão favoráveis assim. Para além de se tratar de um livro que pode se inscrever no campo da autoajuda, não o é assim definido aqui, mas compreendido como um estímulo ao leitor para tomar e retomar quantas vezes desejar, quando quiser fazê-lo em qualquer tempo e espaço. Isso, pois, as leituras realizadas sempre serão outras, novas, contínuas, tanto quanto os sentidos atribuídos também o poderão ser.

Logo, a linguagem compreensível que envolve o leitor às perspectivas filosóficas, históricas, culturais e sociais apresentadas pelos autores, as quais se entrelaçam a partir da heterogeneidade de discursos constituída por outros pensadores e filósofos dos quais Cortella e Karnal (2020) engendram ao longo da obra, imprimindo a partir de exemplos de vida, as marcas históricas de vida pessoal e profissional dos autores. Tais reflexões e inquietações dos próprios autores instigam o leitor a fazê-las e a tê-las sobre si, sobre suas mais diferentes formas de agir, de pensar, de ser na relação sobre/com o outro e consigo (BAKHTIN, 2011[1979]). Trajetórias que desenhamos daquilo que almejamos, que queremos, que buscamos e, sobretudo, do valor que atribuímos a todo esse percurso em se pensando nas relações dialógicas que assumimos conosco e com outro (BAKHITIN, 2011[1979]). Essas interações também vão definir as rotas, o rumo que vamos seguir e as posições que seremos convocados a ocupar durante nossa existência em diferentes esferas sociais de atividade humana (no trabalho, na família, na religião, entre outras). Segundo discute Bakhtin, pensador da Filosofia da Linguagem, "viver é tomar posições continuamente, é enquadrar-se em um sistema de valores e, do interior dele, responder axiologicamente" (GEGe, 2009, p. 64, grifos do grupo).

Neste sentido, tais marcas impressas por Cortella e Karnal (2020) em suas escrituras sinalizam que apesar de haver várias incógnitas nos percursos históricos que traçamos, só somos quem somos no/pelo e com o outro. Numa perspectiva enunciativa-discursiva "[c]onstituímo-nos e nos transformamos sempre através do outro. A alteridade é fundamento da identidade. Relação é a palavra-chave na proposta de Bakhtin. Eu apenas existo a partir do Outro" (GEGe, 2009, p. 13-14, grifos do grupo).

Assim, Cortella e Karnal (2020) discorrem em nove breves capítulos, a saber: "Eu não pedi para nascer"; Livres até que ponto?; Por que algumas pessoas se matam?; O que nos trouxe até aqui?; Dom, vocação ou esforço?; Nada é possível; tudo é possível; Menos inspiração, mais transpiração: Há destino?; "Eu, por mim”, seguido de um glossário de grandes personagens que compuseram parte da história mundial, problematizando sobre aquilo que escolhemos e aquilo que também não, consequentemente, aquilo que foge ao nosso controle. "Ou seja, o conjunto de fatores que podem ou não levar a uma situação" (CORTELLA; KARNAL, 2020, p. 38-39).

O que apontam os autores baseia-se naquilo que o ser, sempre em processo, busca de respostas. Mas o que ocorre é que, muitas vezes, há respostas para confirmar aquilo que queremos ouvir. Há meia respostas, aquilo que em parte nos contentamos com o que desejaríamos ouvir e a outra parte não. E, há ainda aquilo que não se pode responder porque de fato não há respostas para todas as perguntas, portanto, talvez uma saída poderia ser que a resposta é não ter respostas. Conforme sinalizam os autores, "[s]omos, portanto, frutos de uma historicidade, mas ela não nos explica. Ela apenas explica aquele momento. Dentro disso, existem contradições enormes, possibilidades equivocadas" (CORTELLA; KARNAL, 2020, p. 39).

No primeiro capítulo "Eu não pedi para nascer" os autores discorrem sobre diferentes significados a que se pode dar a este enunciado. Pode querer justificar que não sou responsável por aquilo que faço ou ainda que "“eu não tenho compromisso" com estado de coisas” (CORTELLA; KARNAL, 2020, p. 8), o que demarca um sujeito situado historicamente ao tentar, de certa maneira, se eximir desta responsabilidade e nos creditaria pensar até que ponto somos livres, até que pontos temos liberdade. 
“Livres até que ponto?”, título do segundo capítulo, Cortella e Karnal (2020) nos provocam a pensar sobre a ideia da liberdade. Se somos livres para escolher, para decidir, para seguir por onde desejamos, esse "meu livre-arbítrio é livre onde, de que modo, em que condições?" (CORTELLA; KARNAL, 2020, p. 18). Neste sentido, existir estaria relacionado a viver enfrentando ora a dor, ora os obstáculos que vivenciamos cotidianamente, em diferentes contextos sociais, econômicos, geográficos, culturais. E tal dor, portanto, não nos pressiona, não nos obriga como a felicidade. Conforme reforçam os autores, "[q]uanto mais tragédia temos, mais somos livres". Porque esse pensamento faz com que não dependa de nós as escolhas desses momentos mais árduos, mais difíceis, por não se prever ações que ainda estão por vir, acontecer.

No terceiro capítulo intitulado "Por que algumas pessoas se matam?", os autores problematizam o motivo que leva algumas pessoas a escolherem tirar a sua vida. Ao passo que mencionam que pessoas se matam porque sentem muita dor, seja ela de cunho religioso, político, emocional ou psíquico. Por outro lado, há os que não têm a possibilidade de pensar sobre o tema, muito menos fazê-lo. Isso porque são pessoas que, como nós, lutam cotidianamente para sobreviver, driblando as adversidades da vida e, consequentemente, não gozam de tempo para executá-lo. Cortella e Karnal (2020) exemplificam esse momento a partir do contexto social do mendigo: por que este ator social não se mata? Porque vive em busca do que comer, pensa o tempo inteiro em se alimentar e, deste modo, seu pensamento não estaria direcionado para pensar em suicídio. "[Q]uando você lembra que aquele que não tem nada a perder, o despossuído, tem tanta coisa séria para dar conta, como, por exemplo, se ele almoçará naquele dia, que não dá tempo disso, de pensar em se matar" (CORTELLA; KARNAL, 2020, p. 31-32).

“O que nos trouxe até aqui?", quarto capítulo é tecido a partir de como nos constituímos socialmente na/pela história. O modo como construo a minha própria trajetória daquilo que vou significando, do como e do porquê em dado tempo e espaço eu atribuo esse ou aquele sentido as minhas, as tuas, as nossas escolhas, da maneira como nos importamos com determinado assunto, com determinada situação da qual nos perpassa e nos situa, é marcada pela historicidade de nossas práticas sociais. Os autores citam grandes momentos da história como a I Guerra Mundial, a Revolução Francesa, a Paz Armada, entre outros a fim de destacar que não se trata de refletir sobre as causas desses marcos históricos, mas sim de problematizar sobre "o conjunto de fatores que podem ou não levar a uma situação", ou seja, a sua historicidade (CORTELLA; KARNAL, 2020, p. 38-39). No tocante à história, concordamos com os autores em entendê-la como contraditória, constituída por sua dialética/dialogia (BAKHITIN, 2011[1979]), descontruindo a linearidade e a organização. Trata-se de compreendê-la como processual, contínua, buscando "entender como funciona aquele momento", seja ele relacionado a nossa vida cotidiana, seja ligado às questões econômicas, políticas, culturais (CORTELLA; KARNAL, 2020, p. 39).

Cortella e Karnal (2020) tecem o quinto capítulo “Dom, vocação ou esforço?” sobre o desenvolvimento humano, nossas capacidades e habilidades, concebidas como um dom ou uma vocação. Os autores fazem uma crítica a isto, afirmando que "[o] sucesso, seja como o consideramos, precisa do esforço do indivíduo" (CORTELLA; KARNAL, 2020, p. 54). Ou seja, nos exigirá muita dedicação, muito esforço, muito empenho, portanto, muita prática. Além disso, assinalam que é preciso nessas construções que exigem zelo, responsabilidade e disciplina, imprimir uma assinatura, um sentido próprio que cada um/cada uma vai dar àquilo que se propõe a fazer, aquilo que elege como sendo importante para sua vida, pontualmente aqui, no tocante ao campo profissional.

"Nada é possível; tudo é possível" é o sexto capítulo e apresenta uma dicotomia entre o tudo e nada. Um tudo que quereremos abraçar e fazer ao mesmo tempo e um nada que, muitas vezes, não nos é possível porque não se torna algo atingível. "Não podemos ser tudo, mas podemos ser várias coisas na nossa trajetória" (CORTELLA; KARNAL, 2020, p. 55). Esse meio termo descrito pelos autores permite ao ser humano construir sua trajetória, as escolhas que faz e as que lhe fogem ao controle, que independem de si ao passo que se constitui e constitui o outro nas/pelas interações sociais e históricas as quais está inscrito. Então, "Viver, a que se destina?", implica refletir, pensar, tomar 
e retomar as diferentes rotas que vamos definindo e redefinindo ao longo desse trajeto chamado de vida, existência. Podemos desejar ser pai, mãe de família. Podemos desejar estudar, trabalhar. Enfim, como eternos aprendizes, temos indefinições, imperfeições, descontinuidades, vivências, minhas, tuas, nossas, somos humanos.

O sétimo capítulo "Menos inspiração, mais transpiração: Há destino?” aponta para direções as quais não há certo e errado, não há lógica, não há determinismo para as escolhas que fizemos e as que não fizemos. "Muitas vezes não existem nenhum destino, não existe nenhuma vocação, não existe nada pré-escrito, mas, quando surge uma oportunidade, quanto mais bem preparado se estiver, mais essa oportunidade encontrar" (CORTELLA; KARNAL, 2020, p. 69). Cabe estarmos sempre inspirados, motivados a buscar aquilo que desejamos, almejamos, queremos, ao que nos destinamos a fazer na vida, a nos prepararmos para e acima de tudo, pensarmos na nossa sobrevivência. Cabe também transpirarmos talvez mais do que inspiramos, a fim de irmos mais longe, porque assim temos a oportunidade de fugir daquilo que se espera, daquilo que é óbvio. O ser humano, assim, se vê obrigado a pensar e repensar, planejar e replanejar as rotas, muitas vezes inesperadas, dantes nunca navegadas. "[C]aminhamos numa rota que não estava escrita, mas que não poderia ter sido perdida", ou seja, é preciso, viver, experenciar, aprender, a isso que nos destinamos e a ser quem somos (CORTELLA; KARNAL, 2020, p. 69). De todo modo, "[n]ão pedimos para nascer", mas por alguma razão ou por escolha minha, tua, nossa, não desejamos sair, porque "a viagem está agradável” (CORTELLA; KARNAL, 2020, p. 75).

Cortella e Karnal (2020) em "Somos quem escolhermos ser", oitavo capítulo, nos fazem lançar olhar para as escolhas que fizemos e, ao fazê-las, assumimos algumas e outras nos obrigamos a deixar para lá. Não podemos, assim, escolher tudo e o tempo todo. "Por isso, nenhuma escolha, quando feita com inteligência, é isenta de sofrimento" (CORTELLA; KARNAL, 2020, p. 77). Isso, pois, "ao escolher, precisamos ficar numa rota, cuja consequência daquilo que ali acontece é nossa" (CORTELLA; KARNAL, 2020, p. 78). E, deste modo, deixaremos algo para trás que possa ser maior daquilo que "perdemos" como daquilo que "ganhamos" e/ou "recebemos" ao decidir por esta rota e não aquela. Por ser este eu e não aquele outro eu, não há certo e errado no traçado desse caminho escolhido, mas há escolhas que são minhas apenas, não são tuas e tampouco nossas. Contudo, são escolhas constitutivas do eu e do outro nessa teia dialógica que é vida.

Por fim, no nono capítulo "Eu, por mim”, Cortella e Karnal (2020, p. 96) se encaminhando para as reflexões finais, ressaltam que "[e]ntender que o destino da vida é múltiplo, que as escolhas implicam perdas, que a potência de tudo está contida a cada curva da estrada, que eu sou eu e minhas circunstâncias e que é possível interferir, mas não no grau de um ser todo-poderoso, isso deveria nos tornar um pouco mais perfectíveis". Portanto, podemos nos aperfeiçoar ao longo da nossa existência, do trajeto que tivemos a oportunidade de escolher e viver e/ou que em algum momento foram escolhidas por outrem, como o nascer. Essa vida que é cheia de indas e vindas, é constituída de ciclos em que viver se destina a começos e recomeços, tomadas e retomadas em que nos situamos historicamente nas/pelas relações dialógicas com o outro com quem escolhemos também seguir e a quem também nos escolheu para uma caminhada conjunta. 


\section{Referências}

BAKHTIN, Mikhail Mikhailovitch. Estética da criação verbal. Tradução Paulo Bezerra. 6. ed. São Paulo: Martins Fontes, 2011[1979].

GEGe. Grupo de Estudos dos Gêneros do Discurso. Palavra e contraplavras: Glossariando conceitos, categorias e noções de Bakhtin. São Carlos: Pedro \& João Editores, 2009.

Histórico Recebido em: 18/05/2020

Aceito em: 08/10/2020

Financiamento Não houve financiamento 